\title{
Effect Analysis on Combustion and Emission Characteristics of a Rotary Burner Fueled by Biomass Pellet Fuel
}

\author{
Guohai Jia $\mathbb{D},{ }^{1}$ Lijun Li $\mathbb{D},{ }^{1}$ and D. M. Zhang ${ }^{2}$ \\ ${ }^{1}$ College of Mechanical and Electrical Engineering, Central South University of Forestry and Technology, Changsha 410004, China \\ ${ }^{2}$ Department of Industrial Technology, California State University, Fresno, CA 93740-8002, USA \\ Correspondence should be addressed to Lijun Li; junlili1122@163.com
}

Received 11 October 2019; Revised 20 January 2020; Accepted 6 March 2020; Published 21 July 2020

Guest Editor: Yaojie Tu

Copyright (c) 2020 Guohai Jia et al. This is an open access article distributed under the Creative Commons Attribution License, which permits unrestricted use, distribution, and reproduction in any medium, provided the original work is properly cited.

\begin{abstract}
A biomass pellet rotary burner was chosen as the research object, in order to study the influence of excess air coefficient on the combustion phenomenon of biomass rotary burner, the finite element simulation model of a biomass rotary burner was established, and simulation results of a biomass rotary burner were verified by the experiment. The computational fluid dynamics software was applied to simulate the combustion characteristics of biomass rotary burner in a steady-state condition, and the effect of excess air coefficient on temperature field and component concentration field in biomass rotary burner was analyzed. The results show that the flue gas flow rate inside the burner gradually increases with the increase of air velocity, the area with large temperature is mainly concentrated in the middle region of the rotary burner, and the maximum combustion temperature also appeared in the middle region of the combustion chamber, and the formation area of $\mathrm{CO}$ decreases with the increase of excess air coefficient. $\mathrm{CO}_{2}$ is mainly concentrated in the middle region of the burner, and the $\mathrm{CO}_{2}$ generating region decreases with the increase of excess air coefficient. The experimental value of the combustion temperature of the biomass rotary burner is in good agreement with the simulation results.
\end{abstract}

\section{Introduction}

With the rapid development of modern economy and technology, the energy crisis and air pollution from the combustion of fossil fuels have become increasingly serious [1-3]. In order to meet the requirements of resource and environment problems, many researches had been done to improve combustion technologies and look for alternatives to replace fossil fuels $[4,5]$. Biomass pellet fuel is a typical biomass solid forming fuel, with high efficiency, clean, easy to ignition, $\mathrm{CO}_{2}$ near-zero emissions, and so on [6-8]. It can replace coal and other fossil fuels used in cooking, heating, and other civilian areas and boiler combustion, power generation, and other industrial areas $[9,10]$.

In recent years, biomass pellet fuel is being developed rapidly in the EU, North America, and China [11-13]. Another advantage of biomass pellet fuel is that it can be used in small boilers, hot blast furnaces, and heating furnaces. The automatic control system is used to achieve the continuous combustion of biomass pellet fuel burner. After years of research, biomass pellet burners are being developed rapidly. These burners mainly use wood pellets as fuel. Wood pellets have many advantages, such as high calorific value, low ash content, high ash melting point, and being not easy to slag after combustion $[14,15]$.

Khodaei et al. [16] addressed a comparative CFD-based analysis of different drying models. Several submodels were simulated to investigate the evaporation process of different geometries based on standard densified wood pellets. Buchmayr et al. [17] presented an accurate, time-efficient CFD approach for small-scale biomass combustion systems equipped with enhanced air staging. The model can handle the high amount of biomass tars in the primary combustion product at very low primary air ratios. Gas phase combustion in the freeboard was performed by the Steady Flamelet Model (SFM) together with a detailed heptane combustion mechanism. Farokhi et al. [18] presented a computational study to evaluate the influence of turbulence 
and combustion models as well as chemistry schemes on the combustion of an $8-11 \mathrm{~kW}$ small lab-scale biomass furnace. Fagerström et al. [19] used a macro-TGA reactor to determine the release of ash forming elements during devolatilization and char combustion of single pellets. Soft wood and wheat straw were combusted at two temperatures $\left(700^{\circ} \mathrm{C}\right.$ and $\left.1000^{\circ} \mathrm{C}\right)$, and the residual ashes were collected and analyzed for morphology, elemental, and phase composition. Roy et al. [20] presented combustion and emission results obtained using a prototype pellet furnace with $7-32 \mathrm{~kW}$ capacity (designed for burning high ash content pellet fuels) for four biomass pellets: one grass pellet and three wood pellets. Fuel property, gas emissions, and furnace efficiency are compared. Vicente and Alves [21] presented an extensive tabulation of particulate matter emission factors obtained worldwide and critically evaluated. Henderson et al. [22] explained how local economies can benefit from wood pellet manufacturing by expressing the economic multiplier effect of wood pellet plant operations in terms of employment, wages and salaries, and value-added in each of the 13 states in the U.S. South. Nunes et al. [23] studied several studies on the torrefaction of biomass for heat and power applications in the literature, which need to be reviewed and analyzed for further actions in the field, because significant gaps remain in the understanding of the biomass torrefaction process, which necessitate further study, mainly concerning the characterization of the torrefaction chemical reactions, investigation of equipment performance and design, and elucidation of supply chain impacts. Mobini et al. [24] used a dynamic simulation modeling approach to assess the integration of torrefaction into the wood pellet production and distribution supply chain. The developed a model that combined discrete event and discrete rate simulation approaches and allowed considering uncertainties, interdependencies, and resource constraints along the supply chain which were usually simplified or ignored in static and deterministic models.

Proskurina et al. [25] presented an overview of the current status of the Finnish wood pellet business and discussed the main opportunities and challenges facing the future development of the industry. Coelho et al. [26] studied several base case power plants and hybrid biomass/CSP options: wood gasification, refuse-derived fuel pellets, biogas from a wastewater anaerobic digester, and biogas from a landfill and natural gas. Roni et al. [27] investigated the existing cofiring plants with technologies and the availability of biomass resources in different countries of the world. Finally, this paper summarized the major global biomass cofiring initiatives and the prospects of biomass cofiring in securing renewable energy targets. Toklu [28] showed that there is an important biomass energy potential for climate change mitigation and energy sustainability in Turkey. Proskurina et al. [29] evaluated the potential of torrefied biomass in different industries, both power and nonpower generation industries, and considered the impact of such use on the international biomass market. Carvalho et al. [30] compared different technologies, such as CFB air and oxygen gasification, dual fluidized bed (DFB) steam gasification, and bio-synthetic natural gas (bioSNG) production, focusing on the use of the product gas in an iron ore pelletizing process located in the Southeast of Brazil. García et al. [31] analyzed thirteen alternative raw biomass samples and compared them with briquette, wood pellets, and charcoal and considered the data of their proximate, ultimate, and calorimetric analysis and physical properties. Silva et al. [32] evaluated the application potential of torrefaction in the solid fuel's production from lignocellulosic biomasses in Brazil. $\mathrm{Xu}$ et al. [33] evaluated the reductions in PM2.5, organic carbon (OC) and elemental carbon (EC) emissions by comparing emission factors (EFs) among 19 combinations of biofuel/residential stove types measured using a dilution sampling system. Ahn and Jang [34] manufactured and tested a prototype of a $230 \mathrm{~kW}$ class wood pellet boiler employing a four-step grate. Ndibe et al. [35] investigated cofiring characteristics of torrefied biomass fuels at $50 \%$ thermal shares with coals and $100 \%$ combustion cases. Kraszkiewicz et al. [36] analyzed the results of the $\mathrm{CO}, \mathrm{NO}$, and $\mathrm{SO}_{2}$ emission from burning pellets of oil cake, rape straw, and birch sawdust in the low-temperature water boiler of the top combustion. Chai and Saffron [37] optimized the biomass upgrading depot capacity and biomass feedstock moisture to obtain the minimum production cost at the depot gate to produce woody biofuels.

In this paper, a biomass pellet rotary burner with the spiral cleaning and slagging device was chosen as the research object in order to study the influence of excess air coefficient on the combustion efficiency. According to the combustion characteristics of the biomass (wood pellet), a high-efficiency double-layer combustion drum device has been designed to achieve a better flow distribution in this study. The flow velocity distribution characteristics in the burner have an important effect on the combustion efficiency of the biomass (wood pellet). The flow field distribution and combustion field distribution of the new biomass rotary burner are studied, which can reduce the test workload and shorten the design cycle. The CFD software was applied to simulate the combustion characteristics of biomass rotary burner in steady condition, and the effects of the excess air ratio on the temperature field and component concentration field in the biomass rotary burner were analyzed.

\section{Numerical Model}

2.1. Physical Model of Biomass Rotary Burner. In order to improve the thermal efficiency of the biomass rotary burner, a rotary combustion chamber has been used in the biomass rotary burner for reducing the pollutants. A screw feed device is used to control the appropriate amount of biomass (wood pellet). The schematic diagram of the biomass rotary burner is shown in Figure 1 which is mainly constituted by the spiral feeding mechanism, rotary combustion chamber, small combustion chamber, connecting flange, and other components.

When the burner is working, the biomass pellets are fed from the feed spiral tube into the rotary combustion chamber. The air is blown into the rotary combustion chamber through the secondary air pores to make the biomass particles burn completely. The combustion characteristics of the burner in the steady state are studied in the paper. 


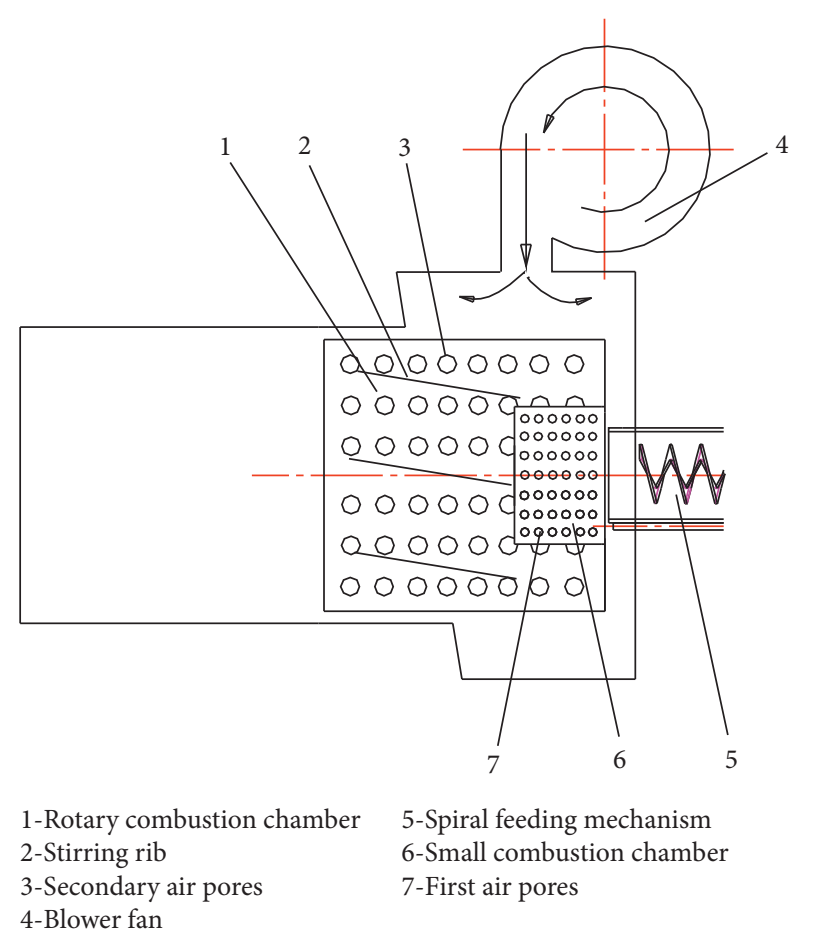

FIGURE 1: Schematic of biomass pellet rotary burner.

2.2. Mathematical Model. In this work, the combustion characteristics of the biomass rotary burner were studied by Fluent software. In the numerical calculation, the turbulent flow adopts the $k-\varepsilon$ equation model, and the P-1 model was used to simulate the radiative heat transfer. The discrete phase particle trajectory was adopted. A power-diffusion limiting model was used in the stochastic tracking model for combustion. A two-step competitive reaction model was adopted for calculating volatile pyrolysis, and a mixture fraction/probability density function (PDF) was used for simulating gas phase turbulent combustion.

In the fluid simulation of biomass rotary burner, it is regarded as steady-state turbulent motion. The flow and heat transfer conservation equations of mass, momentum, and energy are as follows.

The mass conservation equation is

$$
\operatorname{div}(\rho U)=0,
$$

where $\rho$ is the fluid density and $U$ is the fluid velocity vector.

The momentum conservation equation is

$$
\left\{\begin{array}{l}
\operatorname{div}(\rho u U)=\operatorname{div}(\mu \operatorname{grad} u)-\frac{\partial p}{\partial x}+S_{u}, \\
\operatorname{div}(\rho v U)=\operatorname{div}(\mu \operatorname{grad} v)-\frac{\partial p}{\partial y}+S_{v} \\
\operatorname{div}(\rho w U)=\operatorname{div}(\mu \operatorname{grad} w)-\frac{\partial p}{\partial z}+S_{w}
\end{array}\right.
$$

where $p$ is the fluid pressure, $\mu$ is the dynamic viscosity, and $S_{u}, S_{v}$, and $S_{w}$ are the generalized source terms for the momentum conservation equation.
The energy conservation equation is

$$
\operatorname{div}(\rho U T)=\operatorname{div}\left(\frac{h}{c_{p}} \operatorname{grad} T\right)+S_{T},
$$

where $c_{p}$ is the specific heat capacity of fluid, $T$ is the fluid temperature, $h$ is the heat transfer coefficient of fluid, and $S_{t}$ the is viscous dissipation term.

The turbulence kinetic equation and the turbulence stress equation which reflect the influence of the turbulence pulsation on flow can be obtained by the $k-\varepsilon$ equation in the following form:

$$
\frac{\partial\left(\rho k u_{i}\right)}{\partial x_{i}}=\frac{\partial}{\partial x_{j}}\left[\left(\mu+\frac{\mu_{t}}{\sigma_{k}}\right) \frac{\partial k}{\partial x_{j}}\right]+G_{k}-\rho \varepsilon+S_{k},
$$

where $k$ is the turbulent kinetic energy, $\mu_{t}$ is the turbulent viscosity, $G_{k}$ is the generation term of the turbulent kinetic $k$ caused by mean velocity gradient, $S_{k}$ is the source term of turbulent kinetic energy, and $\sigma_{k}$ is the Prandtl number corresponding to the turbulent kinetic $k$.

$$
\frac{\partial\left(\rho \varepsilon u_{i}\right)}{\partial x_{i}}=\frac{\partial}{\partial x_{j}}\left[\left(\mu+\frac{\mu_{t}}{\sigma_{\varepsilon}}\right) \frac{\partial \varepsilon}{\partial x_{j}}\right]+\frac{\varepsilon}{k}\left(C_{1 \varepsilon} G_{k}-\rho \varepsilon G_{2 \varepsilon}\right)+S_{\varepsilon},
$$

where $\varepsilon$ is the turbulent dissipation rate, $S_{\varepsilon}$ is the turbulent dissipation source, $\sigma_{\varepsilon}$ is the Prandtl number corresponding to the turbulent kinetic energy dissipation $\varepsilon$, and $C_{1 \varepsilon}$ and $C_{2 \varepsilon}$ are the empirical constants, $\sigma_{k}=1.0, \sigma_{\varepsilon}=1.3, C_{1 \varepsilon}=1.44$, and $C_{2 \varepsilon}=1.92$.

In the mixed fraction model, the instantaneous thermochemical parameters of the fluid are related to the mixing fraction. The mixing fraction can be calculated by equation (6) according to the atomic mass fraction of the fuel and oxidant including the inert component:

$$
f=\frac{Z_{i}-Z_{i, \mathrm{ox}}}{Z_{i, \text { fuel }}-Z_{i, \mathrm{ox}}}
$$

where $Z_{i}$ is the elemental mass fraction of element $i$, the subscript ox is the value at the inlet of oxidant stream, and fuel is the value at the inlet of the fuel stream. The mixing fraction is the local mass fraction of all components $\left(\mathrm{CO}_{2}\right.$, $\mathrm{H}_{2} \mathrm{O}, \mathrm{O}_{2}$, etc.) including the combusted and unburned fuel stream elements ( $\mathrm{C}, \mathrm{H}$, etc.). The average (time average) mixed fraction and its mean square equation are

$$
\begin{aligned}
\frac{\partial}{\partial t}(\rho \bar{f})+\nabla \cdot(\rho \bar{V} \bar{f})= & \nabla \cdot\left(\frac{\mu_{t}}{\sigma_{t}} \nabla \bar{f}\right)+S_{m} \\
\frac{\partial}{\partial t}\left(\rho \overline{f^{\prime 2}}\right)+\nabla \cdot\left(\rho \bar{V} \overline{f^{\prime 2}}\right)= & \nabla \cdot\left(\frac{\mu_{t}}{\sigma_{t}} \nabla \overline{f^{\prime 2}}\right)+C_{g} \mu_{t}\left(\nabla^{2} \bar{f}\right) \\
& -C_{d} \rho \frac{\varepsilon}{k} \cdot \overline{f^{\prime 2}},
\end{aligned}
$$

where $\bar{V}$ is the average velocity vector, $\mathrm{m} / \mathrm{s} ; \mu_{t}$ is the turbulent viscosity, $\mathrm{kg} /(\mathrm{m} \cdot \mathrm{s}) ; \sigma_{k}$ is the turbulent Prandtl number; $S_{m}$ is the source term caused by chemical reaction, $\mathrm{kg} /\left(\mathrm{m}^{3} \cdot \mathrm{s}\right)$; and 
$C_{g}$ and $C_{d}$ are the model constants which are 2.86 and 2.00, respectively.

For radiant heat flow $q_{r}$, it can be expressed by

$$
q_{r}=\frac{1}{3\left(a+\sigma_{s}\right)-C \sigma_{s}} \nabla G,
$$

where $a$ is the absorption coefficient; $\sigma_{s}$ is the scattering coefficient; $G$ is the incident radiation, $\mathrm{W} / \mathrm{m}^{2}$; and $C$ is the linear anisotropic phase function coefficient.

Introducing the parameter $\Gamma=1 /\left[\begin{array}{ll}3 & \left(a+\sigma_{s}\right)-C \sigma_{s}\end{array}\right]$, equation (8) can be turned into

$$
q_{r}=-\Gamma \nabla G \text {. }
$$

The transport equation for $G$ is

$$
\nabla(\Gamma \nabla G)-a G+4 a \sigma T^{4}=S_{G},
$$

where $\sigma$ is the Stephen-Boltzmann constant, $5.67 \times 10^{-8} \mathrm{~W} /$ $\left(\mathrm{m}^{2} \cdot \mathrm{K}^{4}\right)$; and $S_{G}$ is the source term of user-defined radiation, $\mathrm{W} / \mathrm{m}^{2}$.

When using the P-1 model, the local radiation intensity is used to solve this equation. Equation (11) can be calculated by combining equations (9) and (10):

$$
-\nabla q_{r}=a G-4 a \sigma T^{4}
$$

where $-\nabla q_{r}$ is an expression that can be directly substituted into the energy equation to obtain a heat source due to radiation.

The precipitation of biomass volatiles was simulated using a two-competing-rate model, and the parameter was determined based on the properties of biomass.

$$
\begin{aligned}
\frac{m_{v}(t)}{\left(1-f_{w, 0}\right) m_{p, 0}-m_{a}}= & \int_{0}^{t}\left(\alpha_{1} R_{1}+\alpha_{2} R_{2}\right) \\
& \cdot \exp \left(-\int_{0}^{t}\left(R_{1}+R_{2}\right) \mathrm{d} t\right) \mathrm{d} t
\end{aligned}
$$

where $m_{v}(t)$ is the mass of volatiles precipitated at time $t, \mathrm{~kg}$; $f_{w, 0}$ is the initial volatile mass fraction of the particles; $m_{p, 0}$ is the initial particle mass of the jet source, $\mathrm{kg} ; m_{a}$ is the ash content of the particles, $\mathrm{kg} ; \alpha_{1}$ and $\alpha_{2}$ are production rate factors; and $R_{1}$ and $R_{2}$ are competitive precipitation rate constants, controlling the precipitation rate in different temperature ranges, $R_{i}=A_{i} \exp \left(-E_{i} / R T_{p}\right), \mathrm{kg} /(\mathrm{kg} \cdot \mathrm{s})$.

Through the experimental study, the components attached to the combustion are similar to coke which is very close to the chemical properties of coke. It is assumed that the coke surface reaction rate in the dynamic diffusion control combustion model is simultaneously controlled by the diffusion process and chemical reaction kinetics. The coke combustion rate is

$$
\frac{\mathrm{d} m_{p}}{\mathrm{~d} t}=-\pi d_{p}^{2} p_{\mathrm{ox}} \frac{a R}{a+R}
$$

where $R$ is the chemical reaction rate constant, $R=C_{2} \exp$ $\left(-E / R T_{p}\right), \mathrm{kg} /(\mathrm{kg} \cdot \mathrm{s}) ; M_{p}$ is the current pellet mass of coke, $\mathrm{kg}$; $d_{p}$ is the current particle diameter of coke, $\mathrm{m}$; and $\mathrm{p}_{\mathrm{ox}}$ is the partial pressure of oxidant in vapor phase around the coke particles.

2.3. Computational Mesh and Boundary. Before calculating by numerical simulation method, a $3 \mathrm{D}$ model of biomass pellet rotary burner was established. For making the calculation of the simulation model faster, the burner surface chamfer and fine structure were properly simplified without affecting the accuracy of the calculation. The fluid model in the burner was established by Gambit. The tetrahedral mesh was used to divide the body mesh of the fluid model in the burner. Figure 2 shows a three-dimensional volume model of fluid in the burner with a number of nodes of 133078 and a number of grids of 600240 after grid independence.

In this paper, the boundary conditions are set including the inlet velocity boundary, the pressure outlet boundary, and the wall boundary, and the near-wall region simulation uses the wall function method. The $k-\varepsilon$ model is used to simulate turbulent gas phase flow, the scalar conserved mixed fractional probability density function is used to simulate volatile combustion, and the $\mathrm{P}-1$ radiation model is used for simulation research to calculate the radiation exchange. The kinetic/diffusion control reaction rate model is used to simulate the coke combustion. The distribution characteristic of the solid phase particle is set to uniform. The Lagrange discrete phase model is used to calculate the interaction between the particle phase and the gas phase, and the random orbit model is used to track the particle motion. The WSGGM-domain-based model is used to calculate the absorption coefficient. The inlet boundary is set to the velocity inlet, and the temperature $T$ is set to $300 \mathrm{~K}$. The turbulence intensity is determined by the method of turbulence intensity and hydraulic diameter. The outlet boundary condition is set to the type of pressure outlet. In the process of simulating the adiabatic combustion, the wall is set to an adiabatic wall surface with no heat flux and mass flux. It is assumed that the velocity on the wall surface is zero. The proximate and ultimate analyses of the biomass pellet used in the simulation are listed in Table 1.

The productions of the volatile pyrolysis of the biomass fuel are $\mathrm{CO}, \mathrm{H}_{2}, \mathrm{H}_{2} \mathrm{O}$, and so forth. The pyrolysis equations of the combustion process are as follows:

$$
\begin{gathered}
2 \mathrm{C}(\mathrm{s})+\mathrm{O}_{2}(\mathrm{~g})=2 \mathrm{CO}(\mathrm{g})+246446 \mathrm{~kJ} / \mathrm{kmol} \\
2 \mathrm{CO}(\mathrm{s})+\mathrm{O}_{2}(\mathrm{~g})=2 \mathrm{CO}_{2}(\mathrm{~g})+567414 \mathrm{~kJ} / \mathrm{kmol} \\
\mathrm{C}(\mathrm{s})+\mathrm{CO}_{2}(\mathrm{~g})=2 \mathrm{CO}(\mathrm{g})-160140 \mathrm{~kJ} / \mathrm{kmol} \\
\mathrm{C}(\mathrm{s})+\mathrm{H}_{2} \mathrm{O}(\mathrm{g})=\mathrm{CO}(\mathrm{g})+\mathrm{H}_{2}(\mathrm{~g})-118830 \mathrm{~kJ} / \mathrm{kmol} \\
\mathrm{C}(\mathrm{s})+2 \mathrm{H}_{2} \mathrm{O}(\mathrm{g})=\mathrm{CO}_{2}(\mathrm{~g})+2 \mathrm{H}_{2}(\mathrm{~g})-75114 \mathrm{~kJ} / \mathrm{kmol}
\end{gathered}
$$

$\mathrm{CO}(\mathrm{s})+\mathrm{H}_{2} \mathrm{O}(\mathrm{g})=\mathrm{CO}_{2}(\mathrm{~g})+\mathrm{H}_{2}(\mathrm{~g})-43587 \mathrm{~kJ} / \mathrm{kmol}$ 


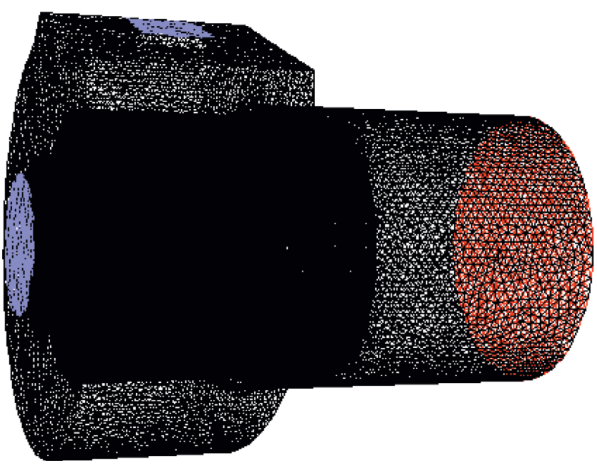

Figure 2: Three-dimensional mesh model of fluid in the burner.

TABLE 1: The proximate and ultimate analyses of China fir (air dry).

\begin{tabular}{lcccc}
\hline \multicolumn{5}{c}{ Proximate analysis } \\
\hline \multicolumn{5}{c}{ Mass ratio (\%) } \\
Moisture & Ash & Volatile & Fixed carbon & Lower heating \\
11.92 & 1.77 & 64.895 & 21.415 & 16.76 \\
\hline
\end{tabular}

For simulating the combustion of the biomass pellet rotary burner, it is necessary to determine the independence between the grid and the calculated results. In the paper, four different density grids of the burner are divided, and the results are shown in Table 2 .

It can be seen from the table that when the grid is increased to 845772 , the maximum temperature of the outer burner remains substantially stable. When the grid is too dense, the simulation time and the computational cost will increase; therefore, the second grid is adopted in the analysis.

2.4. Model Validation. In order to test the simulation model, the team established a test bench for the biomass rotary burner. A schematic diagram of the test device for the biomass rotary burner is shown in Figure 3. It can be seen that the test instruments include thermocouples, flue gas analyzers, fan flow meters, and feed screw speed detection devices. Because this research mainly discusses the combustion efficiency of the burner, the temperature is the best evaluation index. Therefore, temperature measurement is the key condition of model validation. The measuring instruments used in the test are specially customized.

The test steps of the main experiments are as follows:

(1) At the test site, all test devices required for the test platform are installed

(2) Check that all test devices are complete and whether they are consistent with the predetermined size

(3) Check the air tightness of the whole device, and check whether there is any loose connection

(4) Install various sensors and measuring devices

(5) Power on the instrument and ensure that all pipelines are connected

(6) Carry out the experiment according to the experiment manual
TABLE 2: Results of the highest temperature of the outlet dependent on different grid densities.

\begin{tabular}{lcccc}
\hline Calculation method & 1 & 2 & 3 & 4 \\
\hline Grid number & 195064 & 338087 & 623300 & 845772 \\
Highest temperature (K) & 1680 & 1700 & 1790 & 1760 \\
\hline
\end{tabular}

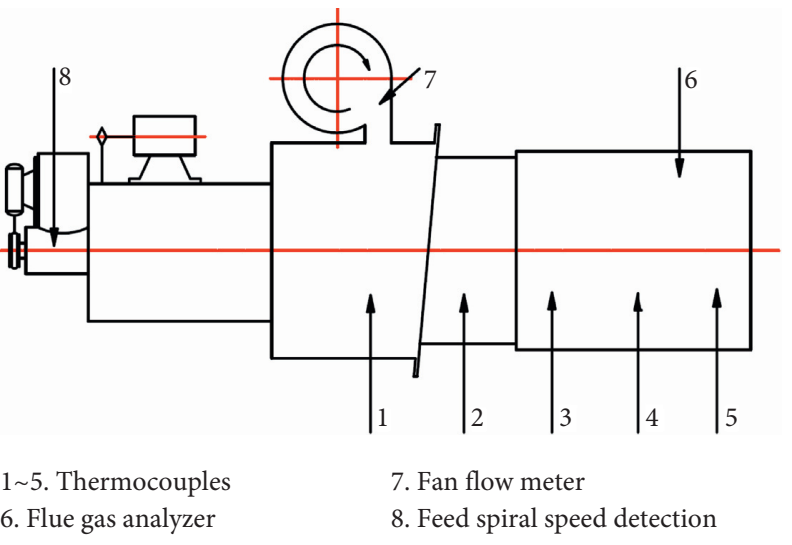

FIGURE 3: Schematic diagram of the thermocouple position in the burner test device.

The biomass pellet fuel used in the test was fir wood pellet fuel which was compressed into a cylindrical shape by a fuel molding machine with a diameter of $5 \mathrm{~mm}$. The processes are as follows:

(1) Convey the wood pellet fuel by the screw conveyor; the conveying capacity of the conveyor was kept at $12 \mathrm{~kg} / \mathrm{h}$.

(2) The hot air gun was energized, and the burner was heated by the hot air for about 10 minutes.

(3) When the hot air gun was energized, the fan started to work, and then the wind was blasted into the combustion chamber.

(4) When the flame was detected, the hot air gun was powered off and stops working. After that, the inlet valve was adjusted to change the intake air volume of the combustion chamber.

Only the measured temperature is reliable due to the error of measuring instruments caused by high temperatures.

It can be seen from Figures 4 and 5 that the experimental values of the combustion temperature of the biomass rotary burner are in good agreement with the simulation results, and the maximum error is $11.9 \%$, because the model is appropriately simplified during the simulation.

\section{Results and Discussions}

In order to make a better comparison with the test results, the fir particle fuel has been chosen as the simulated fuel. Its ultimate and proximate analysis is shown in Table 1 . The feed amount of biomass pellet fuel is set to $12 \mathrm{~kg} / \mathrm{h}$, and the 


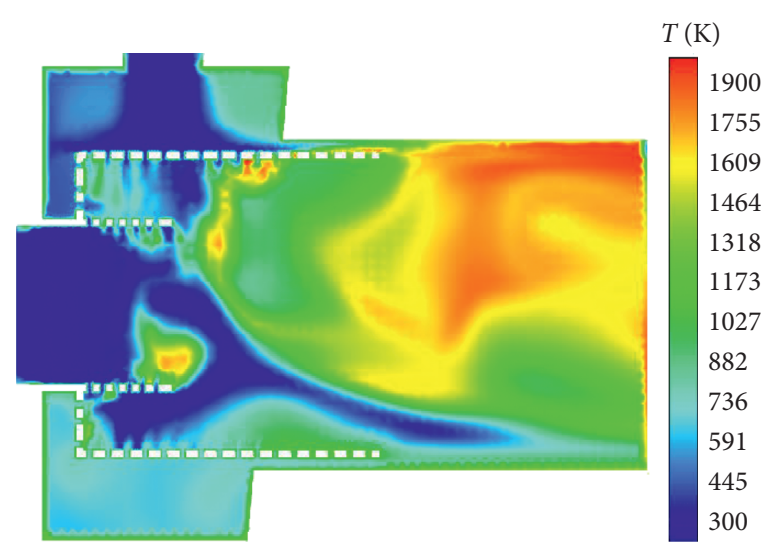

(a)

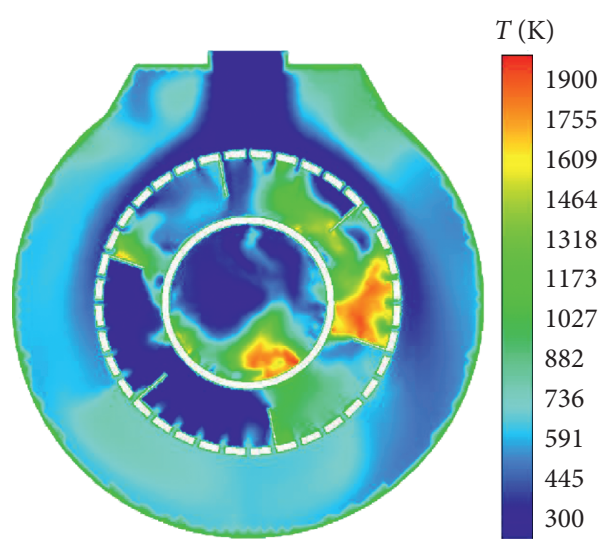

(b)

FIgUre 4: Temperature distribution of the gas phase in the burner. (a) Longitudinal distribution $(\alpha=1.2)$. (b) Horizontal distribution $(\alpha=1.2)(Y=0.364 \mathrm{~m})$.

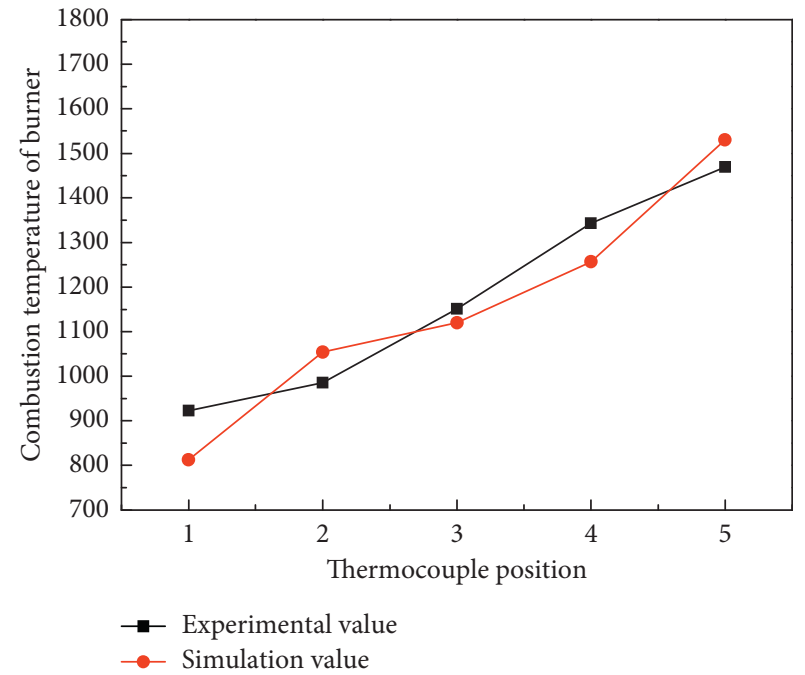

Figure 5: Comparison of simulation and experimental values of the burners' combustion temperature.

temperature field and $\mathrm{CO}, \mathrm{CO}_{2}$, and $\mathrm{O}_{2}$ concentrations of the biomass pellet burner are numerically simulated under four conditions of excess air coefficient of 1.0, 1.4, 1.8, and 2.2 .

3.1. Effect of Excess Air Coefficient on Temperature Distribution. Figure 6 shows the longitudinal distribution of the combustion temperature of the rotary burner under different excess air coefficients. It can be seen from Figure 6 that the temperature changes greatly and is mainly concentrated in the middle region of the rotary burner. The combustion temperature reaches the maximum in the middle region of the combustion chamber. With the increase of excess air ratio, the temperature is correspondingly reduced. When the excess air coefficient $\alpha$ is 1.0, 1.4, 1.8, and 2.2 , the maximum temperature of the rotary combustion chamber is $1700 \mathrm{~K}, 1600 \mathrm{~K}, 1700 \mathrm{~K}$, and $1600 \mathrm{~K}$, respectively.
Figure 7 shows the temperature distribution along the longitudinal centerline of the burner under different excess air coefficients. It can be seen from Figure 7 that the maximum temperature decreases with the increase of excess air coefficient. This is because as the excess air coefficient standing for the fuel is larger, it will be blown to the tail of the burner before the combustion in the combustion chamber is completed. This will lead to an increase in the velocity of the burner outlet, which is consistent with the simulation results.

\subsection{Effect of Excess Air Coefficient on CO Concentration} Distribution. The CO concentration distribution of the burner is shown in Figure 8.

It can be seen that $\mathrm{CO}$ is mainly concentrated near the fuel inlet where the biomass fuel is richer than other areas, so the $\mathrm{CO}$ concentration is also richer, and the $\mathrm{CO}$ generating region decreases when the excess air coefficient increases. When the excess air coefficient $\alpha$ is $1.0, \mathrm{CO}$ is almost distributed throughout the rotary combustion chamber, indicating that the oxygen supply is insufficient in this area. When the excess air coefficient $\alpha$ is 1.4, the CO concentration range decreases with the increase of the oxygen content, and it is limited to the small combustion chamber of biomass rotary burner. When the excess air coefficient $\alpha$ is 2.2 , the $\mathrm{CO}$ concentration range is further reduced, and the range of the maximum $\mathrm{CO}$ concentration is greatly reduced.

Figure 9 shows the distribution of the CO concentration along the axial centerline of the burner under four operating conditions.

It can be seen from the curve in Figure 9 that the $\mathrm{CO}$ concentration under the four working conditions shows an approximate parabolic distribution. It increases rapidly first and then decreases slowly, indicating that the biomass fuel is enough when it enters the combustion chamber, and an incomplete combustion reaction occurs, and then the $\mathrm{CO}$ concentration increases. With the increase of $\mathrm{O}_{2}, \mathrm{CO}$ undergoes further oxidation reaction to form $\mathrm{CO}_{2}$, which causes the $\mathrm{CO}$ concentration to decrease, while the $\mathrm{CO}_{2}$ 


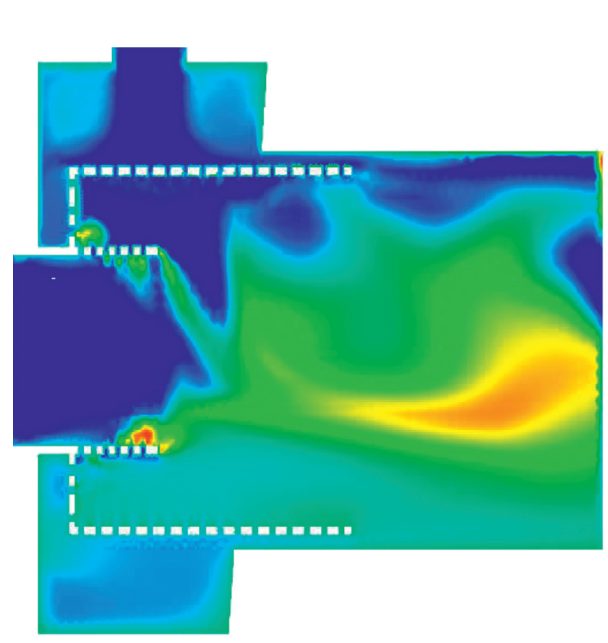

(a)

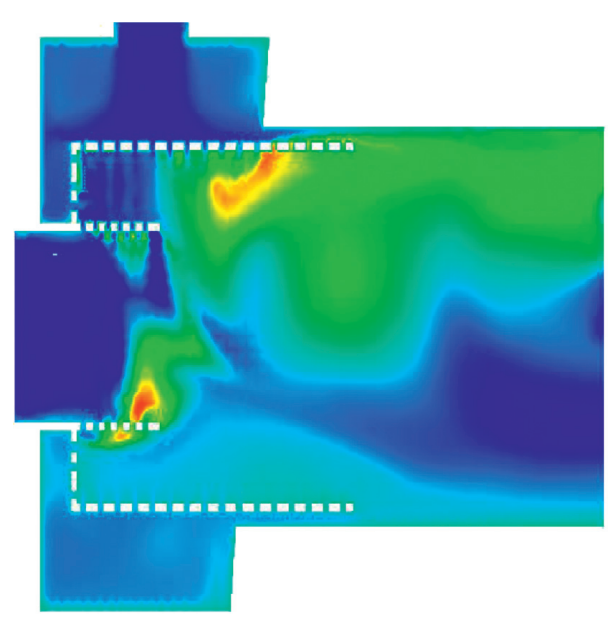

(c)


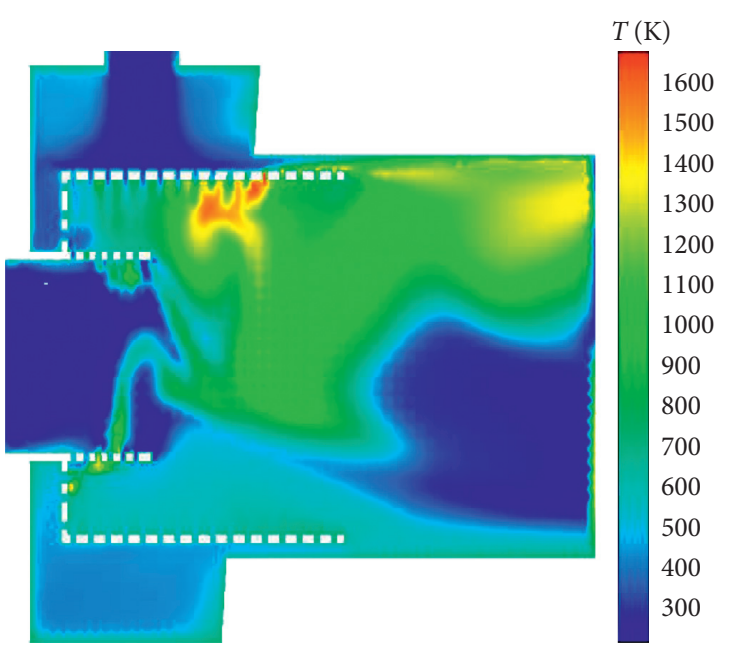

(b)

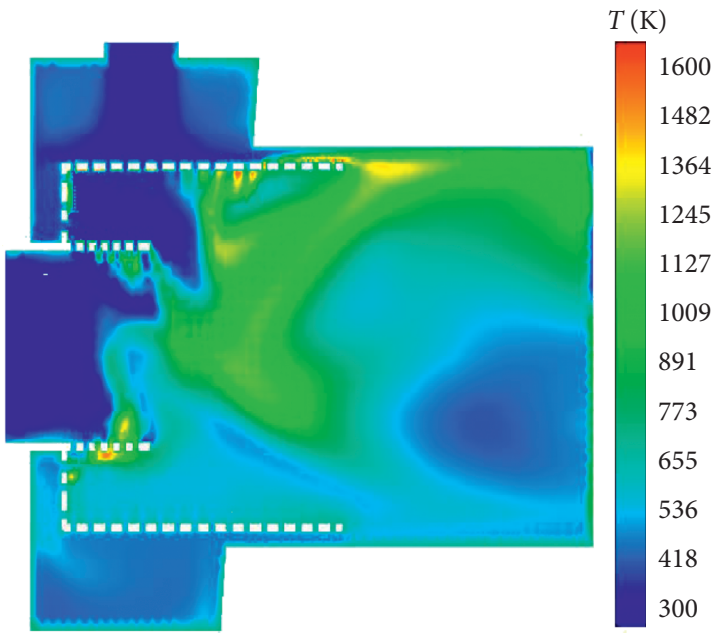

(d)

FIGURE 6: Longitudinal distribution of the combustion temperature of the rotary burner under different excess air coefficients. (a) $\alpha=1.0$. (b) $\alpha=1.4$. (c) $\alpha=1.8$. (d) $\alpha=2.2$.

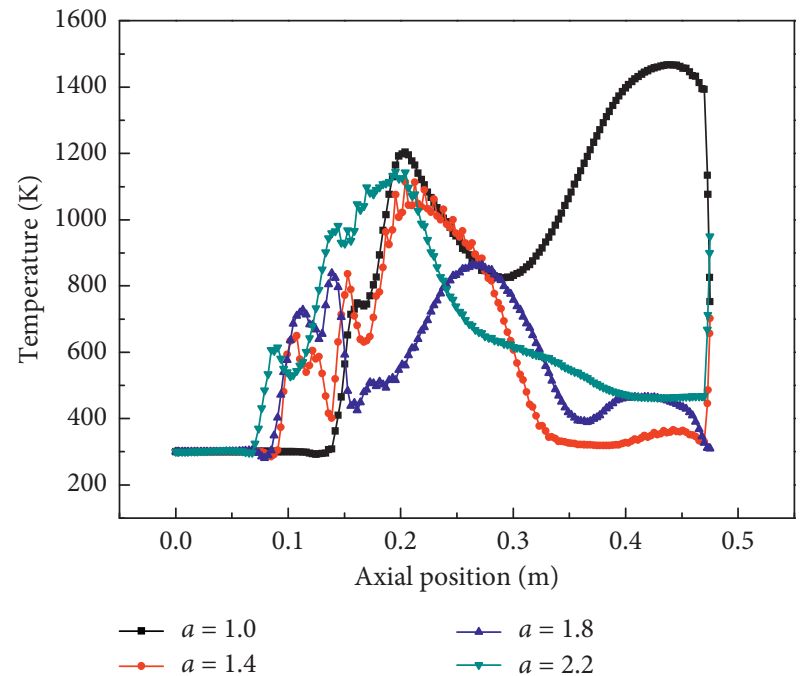

FIgURE 7: Temperature distribution along the longitudinal centerline of the burner under different excess air coefficients. concentration is corresponding to increase. It can be seen that the $\mathrm{CO}$ concentration in the burner gradually decreases with the increase of the excess air coefficient.

\subsection{Effect of Excess Air Coefficient on $\mathrm{CO}_{2}$ Concentration} Distribution. The $\mathrm{CO}_{2}$ concentration distribution of the rotary burner is shown in Figure 10 . The $\mathrm{CO}_{2}$ concentration is mainly concentrated in the middle region of the burner. The $\mathrm{CO}_{2}$ generating region decreases with the increase of the excess air coefficient. When the excess air coefficient $\alpha$ is 1.0, $\mathrm{CO}_{2}$ is almost distributed throughout the rotary combustion chamber, indicating that biomass fuel is almost combusted completely. When the excess air coefficient $\alpha$ is 1.4 , the area of the $\mathrm{CO}_{2}$ concentration range decreases compared with the excess air coefficient 1.0. When the excess air coefficient $\alpha$ is 1.8 , the $\mathrm{CO}_{2}$ concentration range decreases with the increase of the oxygen content, and it is limited to the longitudinal region of the biomass rotary burner. When the excess air coefficient $\alpha$ is 2.4 , the $\mathrm{CO}_{2}$ concentration range is further 


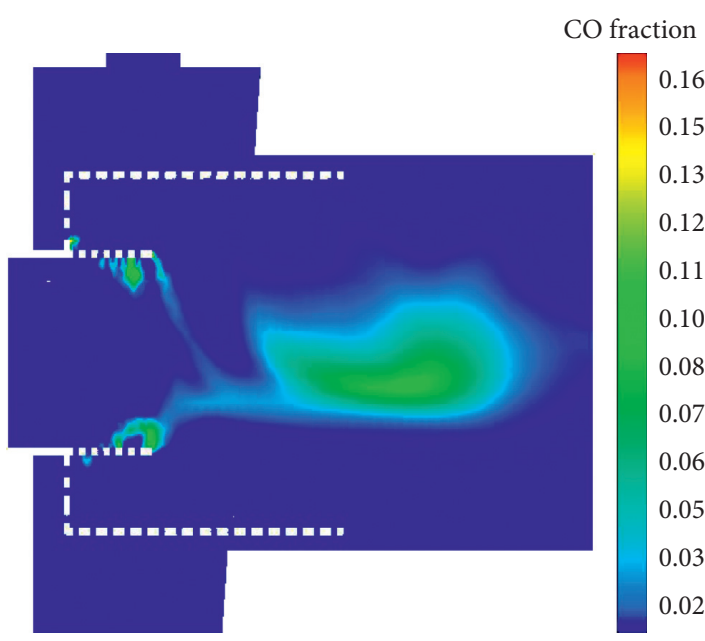

(a)



(c)

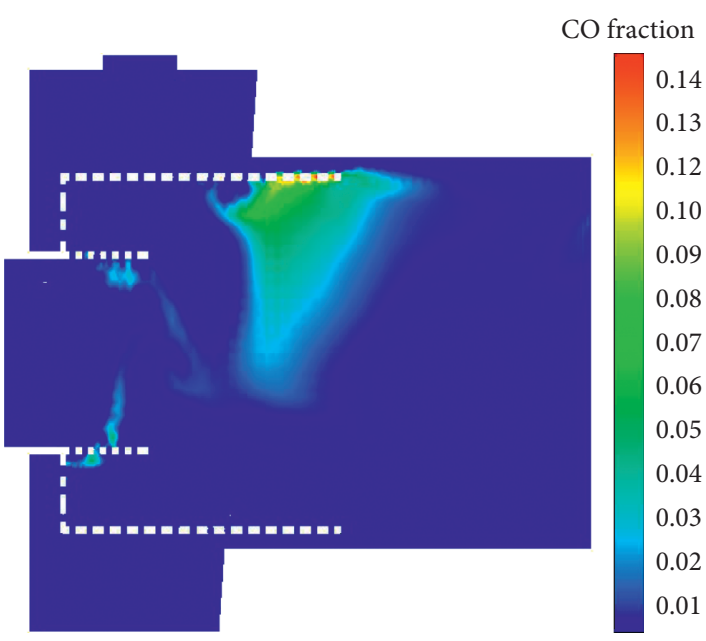

(b)

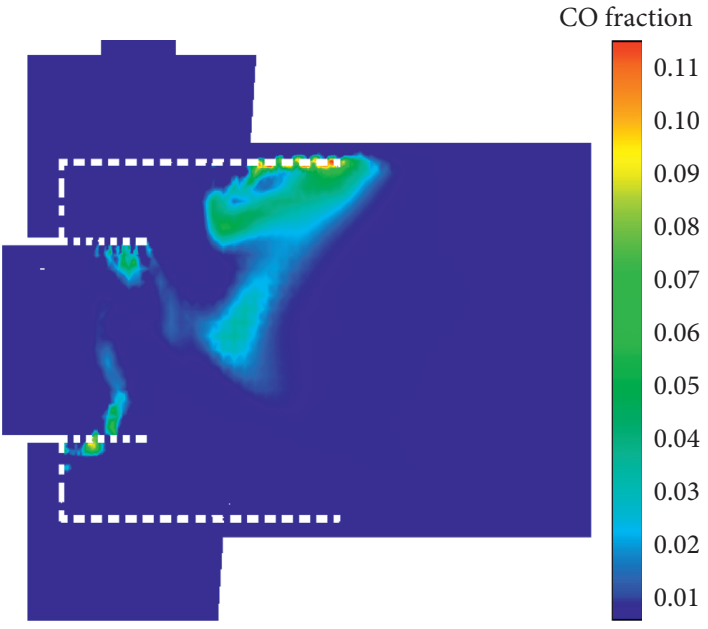

(d)

FIgURE 8: Longitudinal distribution of the CO concentration of the rotary burner under different excess air coefficients. (a) $\alpha=1.0$. (b) $\alpha=1.4$. (c) $\alpha=1.8$. (d) $\alpha=2.2$.

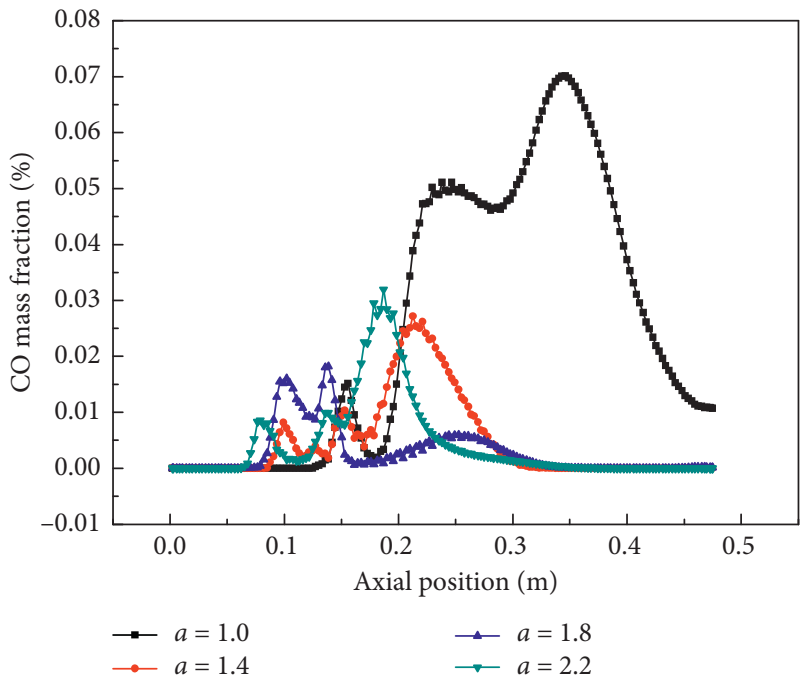

FIGURE 9: CO concentration distribution along the longitudinal centerline of the burner under different excess air coefficients. reduced, and the range of the maximum $\mathrm{CO}_{2}$ concentration is also greatly reduced.

Figure 11 shows the distribution of $\mathrm{CO}_{2}$ concentration along the longitudinal centerline of the burner under four operating conditions. It can be seen from the curve in Figure 11 that the $\mathrm{CO}_{2}$ concentration under the four operating conditions gradually increases with the reaction of combustion, and then it remains stable. As excess air coefficient increases, the $\mathrm{CO}_{2}$ concentration in the burner is gradually reduced.

\subsection{Effect of Excess Air Coefficient on $\mathrm{O}_{2}$ Concentration} Distribution. The $\mathrm{O}_{2}$ concentration distribution of the burner is shown in Figure 12. As shown in Figure 12, $\mathrm{O}_{2}$ is mainly concentrated near the airflow inlet at a lower excess air coefficient. When the excess air coefficient increases, the biomass fuel will burn faster and the $\mathrm{O}_{2}$ region will increase with the increase of excess air coefficient. Figure 13 is a distribution curve of the $\mathrm{O}_{2}$ concentration along the 


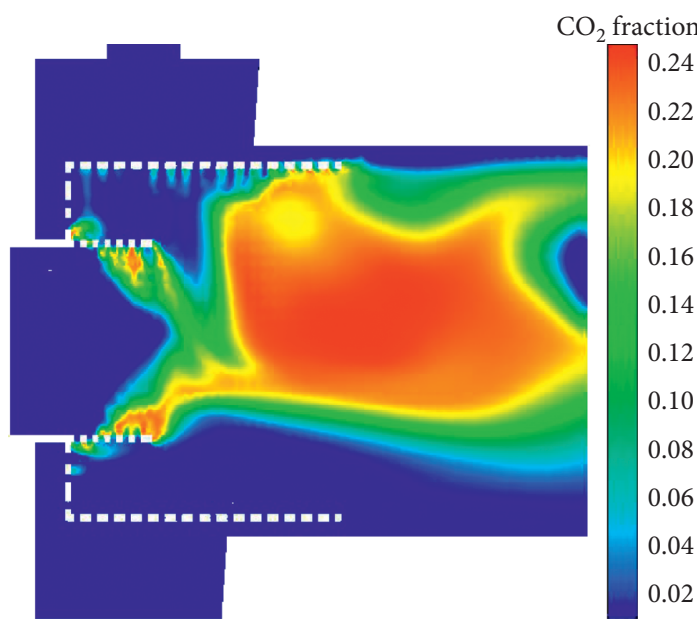

(a)

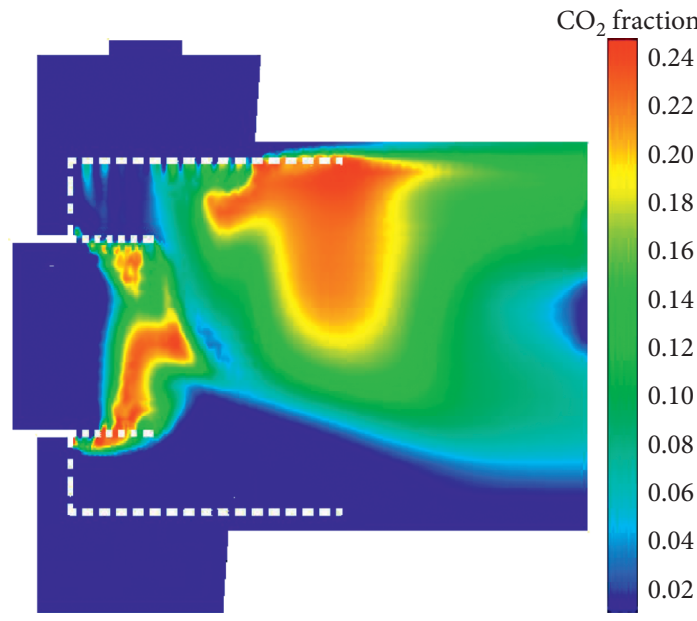

(c)

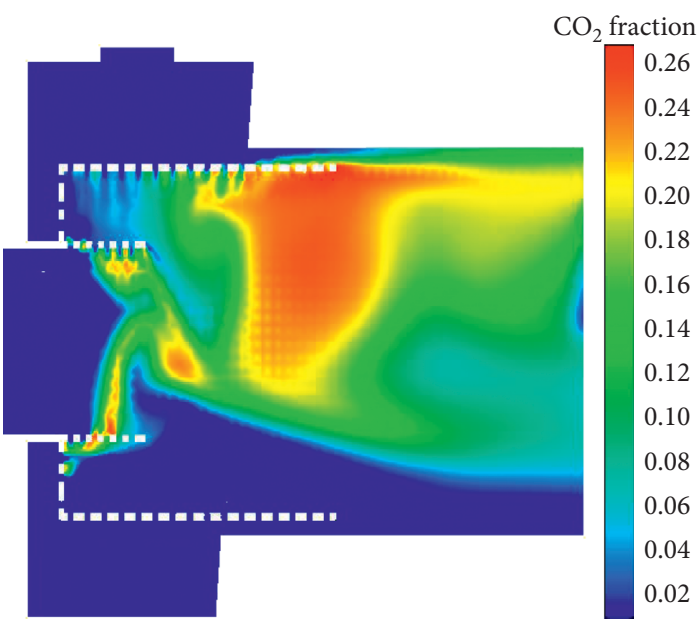

(b)

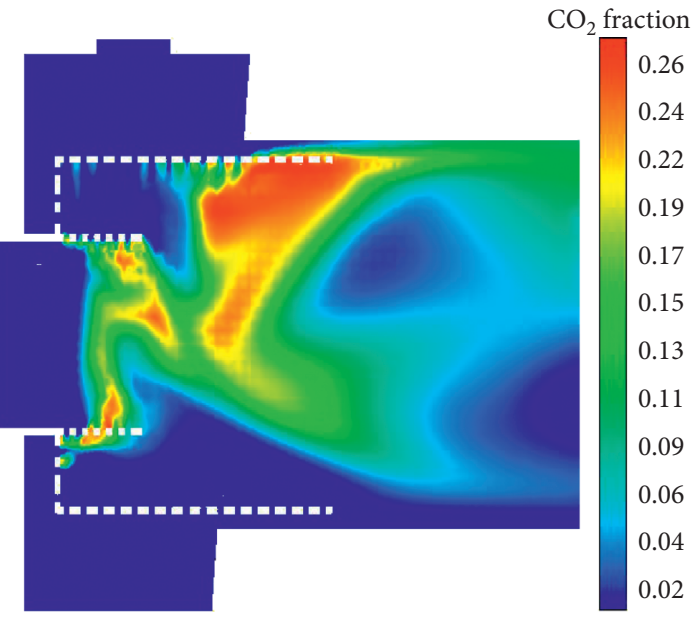

(d)

FIGURE 10: Longitudinal distribution of the $\mathrm{CO}_{2}$ concentration of the rotary burner under different excess air coefficients. (a) $\alpha=1.0$ (b) $\alpha=1.4$. (c) $\alpha=1.8$. (d) $\alpha=2.2$.

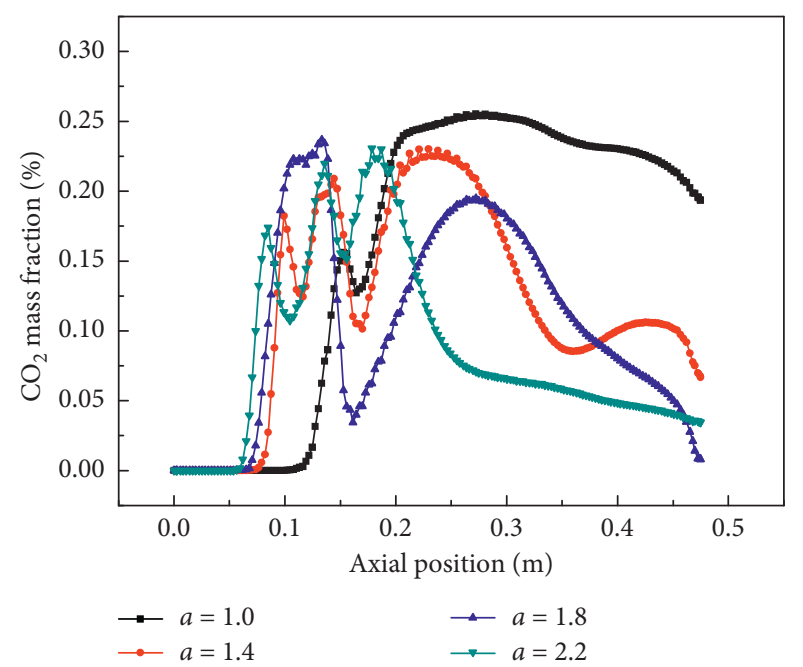

FIGURE 11: $\mathrm{CO}_{2}$ concentration distribution along the longitudinal centerline of the burner under different excess air coefficients. longitudinal centerline of the burner under four operating conditions. As shown in Figure 13, the distribution of $\mathrm{O}_{2}$ concentration gradually increases with the increase of excess air coefficient under the four operating conditions. At a lower excess air coefficient, oxygen is concentrated mainly near the airflow inlet. The middle and lower regions of the burner form a relatively low oxygen atmosphere.

3.5. Current and Future Developments. It is a very important research topic to improve combustion efficiency [38-40] and reduce pollutant emissions [41-46] by changing the shape and structure size of the burners. As for the swirl burner, the latter research should be based on the existing model research and carry out relevant simulation and experimental research. Relevant model modification and parameter sensitivity should be explored. The internal distribution and main distribution trend of the flow field are obtained. The computational fluid dynamics software can be applied to 


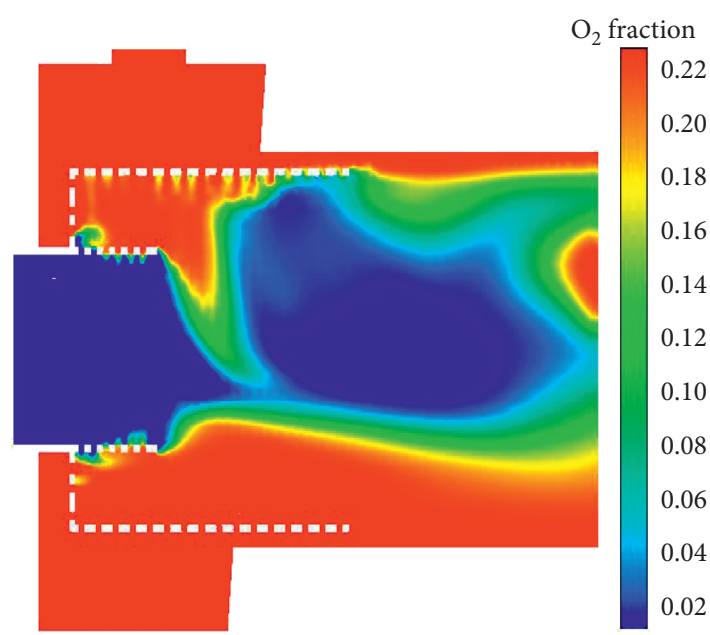

(a)

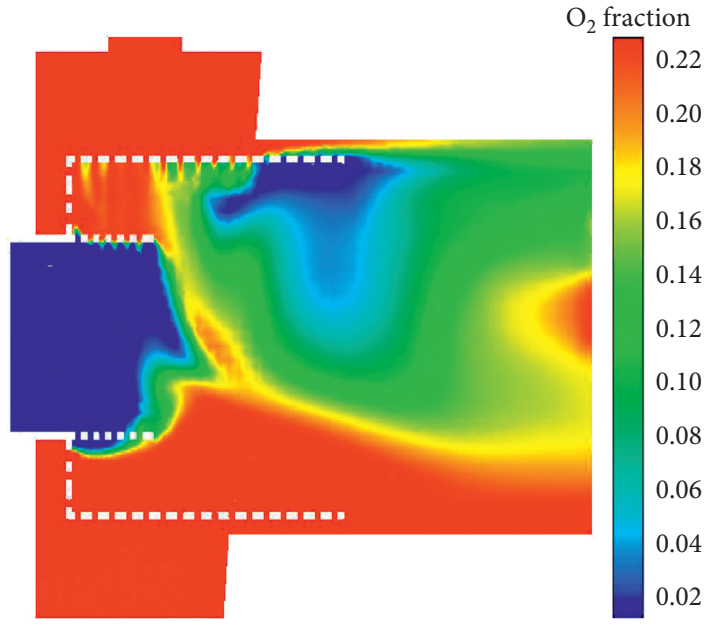

(c)

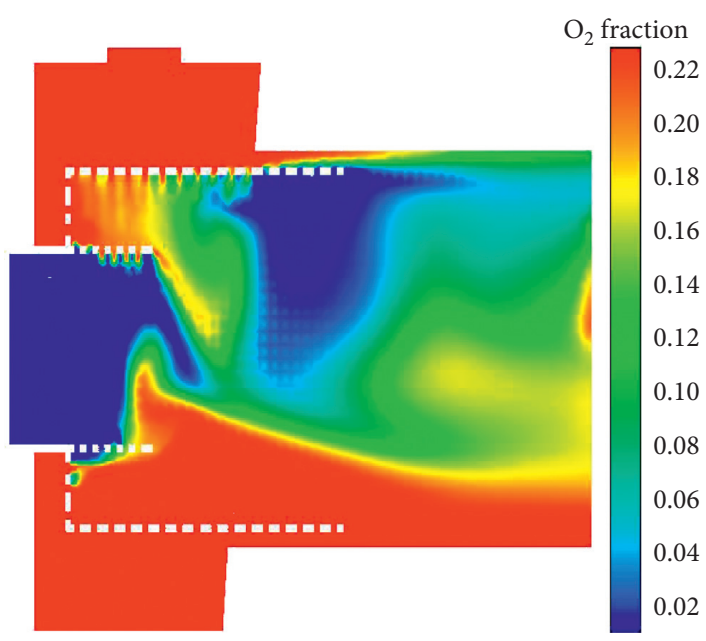

(b)

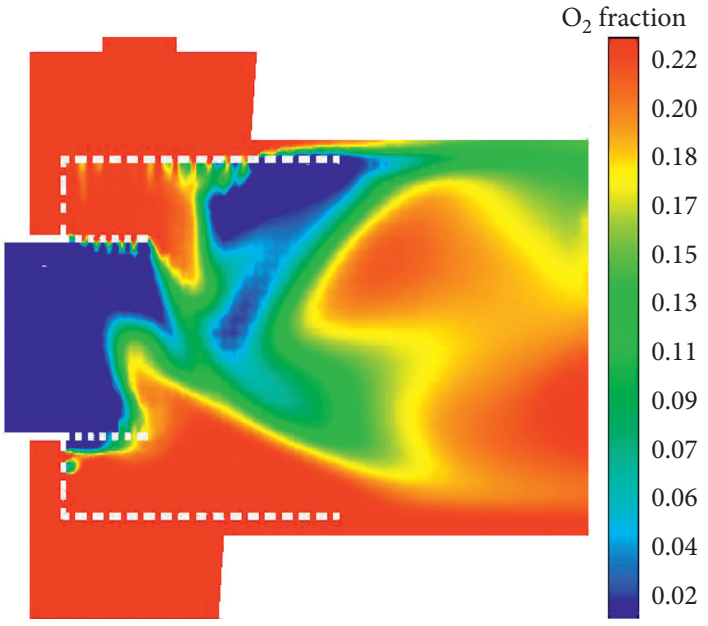

(d)

FIGURE 12: Longitudinal distribution of the $\mathrm{O}_{2}$ concentration of the rotary burner under different excess air coefficients. (a) $\alpha=1.0$. (b) $\alpha=1.4$. (c) $\alpha=1.8$. (d) $\alpha=2.2$.

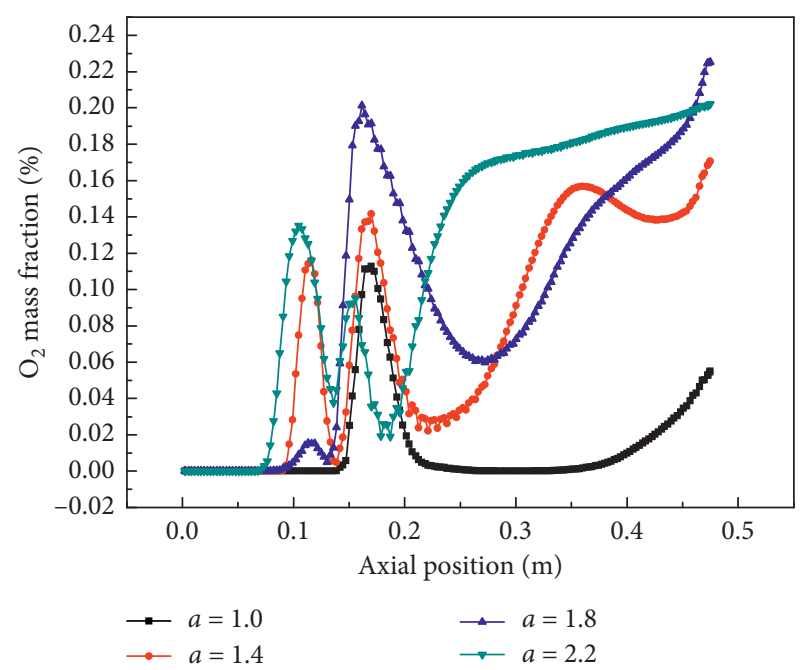

FIgURE 13: $\mathrm{O}_{2}$ concentration distribution along the longitudinal centerline of the burner under different excess air coefficients. simulate the combustion characteristics of the biomass rotary burner in steady condition. The structure of the swirl burner will be more reasonable and it can use fuel efficiently.

\section{Conclusions}

Through the simulation and experimental research on the combustion characteristics of the biomass rotary burner, the conclusions are obtained as follows:

(1) The area where the temperature changes greatly is mainly concentrated in the middle part of the rotary combustor, the combustion temperature reaches the maximum in this region, and the temperature is smaller in other regions. According to the simulation results, the temperature of the burner decreases with the increase of the excess air coefficient.

(2) CO is mainly concentrated near the fuel inlet, because the excess air coefficient is bigger than other 
areas, so $\mathrm{CO}$ is richer than other regions. According to the simulation results, the region of $\mathrm{CO}$ decreases with the increase of the excess air coefficient. $\mathrm{CO}_{2}$ is mainly concentrated in the middle region of the burner and the $\mathrm{CO}_{2}$ generating region decreases with the increase of excess air coefficient. $\mathrm{O}_{2}$ is mainly concentrated near the airflow inlet at lower excess air coefficient, and the biomass fuel burns faster and $\mathrm{O}_{2}$ region also increases with the increase of excess air coefficient.

(3) The experimental values of the combustion temperature of the biomass rotary burner are in good agreement with the simulation results. It is because the model is appropriately simplified in the simulation.

\section{Nomenclature}

$\begin{array}{ll}\rho: & \text { The fluid density, } \mathrm{kg} / \mathrm{m}^{3} \\ c_{p}: & \text { The specific heat of fluid, } \mathrm{J} / \mathrm{kg} \cdot \mathrm{K}) \\ U: & \text { The velocity field, } \mathrm{m} / \mathrm{s} \\ T: & \text { The temperature, } \mathrm{K} \\ h: & \text { The thermal conductivity, } \mathrm{W} /(\mathrm{m} \cdot \mathrm{K}) \\ p: & \text { The fluid pressure, } \mathrm{Pa} \\ \mu: & \text { The dynamic viscosity, Pa.s } \\ S_{u}, S_{v}, & \text { The generalized source terms for the momentum } \\ S_{w}: & \text { conservation equation } \\ \mathrm{K}: & \text { The turbulent kinetic energy, J } \\ \mu_{t}: & \text { The turbulent viscosity, } \mathrm{kg} /(\mathrm{m} \cdot \mathrm{s}) \\ G_{k}: & \text { The generation term of the turbulent kinetic, J } \\ S_{k}: & \text { The source term of turbulent kinetic energy, J } \\ \sigma_{k}: & \text { The Prandtl number } \\ \bar{V}: & \text { The average velocity vector, } \mathrm{m} / \mathrm{s} \\ S_{m}: & \text { The source term caused by chemical reaction, } \mathrm{kg} / \\ & \left.\text { (m }{ }^{3} \cdot \mathrm{s}\right) \\ a: & \text { The absorption coefficient } \\ \sigma_{s}: & \text { The scattering coefficient } \\ G: & \text { The incident radiation, W/m }{ }^{2} \\ C: & \text { The linear anisotropic phase function coefficient } \\ S_{G}: & \text { The source term of user-defined radiation, } \mathrm{W} / \mathrm{m}^{2} .\end{array}$

\section{Data Availability}

The data in this paper are provided by the manufacturer company, which involves product matching and technical parameters of the company.

\section{Conflicts of Interest}

The authors declare that they have no conflicts of interest regarding the publication of this paper.

\section{Acknowledgments}

This work was supported by the China Post-doctoral Science Foundation (2016M592455), Hunan Provincial Education Department's Scientific Research Project (17B278), Hunan Provincial University's Science and Technology Innovation Team Support Plan (2014207), and Central South University of Forestry and Technology's School-level Youth Science Foundation Project (QJ2017006B).

\section{References}

[1] D. Zhao and L. Li, "Effect of choked outlet on transient energy growth analysis of a thermoacoustic system," Applied Energy, vol. 160, pp. 502-510, 2015.

[2] J. Chen, W. Xu, H. Zuo et al., "System development and environmental performance analysis of a solar-driven supercritical water gasification pilot plant for hydrogen production using life cycle assessment approach," Energy Conversion and Management, vol. 184, pp. 60-73, 2019.

[3] H. Zuo, G. Liu, E. Jiaqiang et al., "Catastrophic analysis on the stability of a large dish solar thermal power generation system with wind-induced vibration," Solar Energy, vol. 183, pp. 40-49, 2019.

[4] X. Zhao, G. Wu, E. Jiaqiang et al., "A review of studies using graphenes in energy conversion, energy storage and heat transfer development," Energy Conversion and Management, vol. 184, pp. 581-599, 2019.

[5] E. Jiaqiang, G. Liu, Z. Zhang et al., "Effect analysis on cold starting performance enhancement of a diesel engine fueled with biodiesel fuel based on an improved thermodynamic model," Applied Energy, vol. 243, pp. 321-335, 2019.

[6] E. Jiaqiang, J. Gao, Q. Peng, Z. Zhang, and P. M. Hieu, "Effect analysis on pressure drop of the continuous regenerationdiesel particulate filter based on NO2 assisted regeneration," Applied Thermal Engineering, vol. 100, pp. 356-366, 2016.

[7] E. Jiaqiang, Z. Zhang, J. Chen et al., "Performance and emission evaluation of a marine diesel engine fueled by water biodiesel-diesel emulsion blends with a fuel additive of a cerium oxide nanoparticle," Energy Conversion and Management, vol. 169, pp. 194-205, 2018.

[8] E. Jiaqiang, X. Zhao, L. Xie et al., "Performance enhancement of microwave assisted regeneration in a wall-flow diesel particulate filter based on field synergy theory," Energy, vol. 169, pp. 719-729, 2019.

[9] Z. Zhang, E. Jiaqiang, Y. Deng et al., "Effects of fatty acid methyl esters proportion on combustion and emission characteristics of a biodiesel fueled marine diesel engine," Energy Conversion and Management, vol. 159, pp. 244-253, 2018.

[10] Z. Zhang, E. Jiaqiang, J. Chen et al., "Effects of low-level water addition on spray, combustion and emission characteristics of a medium speed diesel engine fueled with biodiesel fuel," Fuel, vol. 239, pp. 245-262, 2019.

[11] D. Zhao, E. Gutmark, and P. de Goey, "A review of cavitybased trapped vortex, ultra-compact, high-g, inter-turbine combustors," Progress in Energy and Combustion Science, vol. 66, pp. 42-82, 2018.

[12] D. Zhao, C. Ji, X. Li, and S. Li, "Mitigation of premixed flamesustained thermoacoustic oscillations using an electrical heater," International Journal of Heat and Mass Transfer, vol. 86, pp. 309-318, 2015.

[13] J. Chen, Y. Fan, E. Jiaqiang et al., "Effects analysis on the gasification kinetic characteristics of food waste in supercritical water," Fuel, vol. 241, pp. 94-104, 2019.

[14] E. Jiaqiang, G. Liu, T. Liu et al., "Harmonic response analysis of a large dish solar thermal power generation system with wind-induced vibration," Solar Energy, vol. 181, pp. 116-129, 2019.

[15] Y. Li, W. Tang, Y. Chen, J. Liu, and C.-f. F. Lee, "Potential of acetone-butanol-ethanol (ABE) as a biofuel," Fuel, vol. 242, pp. 673-686, 2019. 
[16] H. Khodaei, G. H. Yeoh, F. Guzzomi, and J. Porteiro, “A CFDbased comparative analysis of drying in various single biomass particles," Applied Thermal Engineering, vol. 128, pp. 1062-1073, 2018.

[17] M. Buchmayr, J. Gruber, M. Hargassner, and C. Hochenauer, "A computationally inexpensive CFD approach for smallscale biomass burners equipped with enhanced air staging," Energy Conversion and Management, vol. 115, pp. 32-42, 2016.

[18] M. Farokhi, M. Birouk, and F. Tabet, “A computational study of a small-scale biomass burner: the influence of chemistry, turbulence and combustion sub-models," Energy Conversion and Management, vol. 143, pp. 203-217, 2017.

[19] J. Fagerström, E. Steinvall, D. Boström, and C. Boman, "Alkali transformation during single pellet combustion of soft wood and wheat straw," Fuel Processing Technology, vol. 143, pp. 204-212, 2016.

[20] M. M. Roy, A. Dutta, and K. Corscadden, "An experimental study of combustion and emissions of biomass pellets in a prototype pellet furnace," Applied Energy, vol. 108, pp. 298307, 2013.

[21] E. D. Vicente and C. A. Alves, "An overview of particulate emissions from residential biomass combustion," Atmospheric Research, vol. 199, pp. 159-185, 2018.

[22] J. E. Henderson, O. Joshi, R. Parajuli, and W. G. Hubbard, "A regional assessment of wood resource sustainability and potential economic impact of the wood pellet market in the U.S. South," Biomass and Bioenergy, vol. 105, pp. 421-427, 2017.

[23] L. J. R. Nunes, J. C. O. Matias, and J. P. S. Catalão, “A review on torrefied biomass pellets as a sustainable alternative to coal in power generation," Renewable and Sustainable Energy Reviews, vol. 40, pp. 153-160, 2014.

[24] M. Mobini, J.-C. Meyer, F. Trippe, T. Sowlati, M. Fröhling, and F. Schultmann, "Assessing the integration of torrefaction into wood pellet production," Journal of Cleaner Production, vol. 78, pp. 216-225, 2014.

[25] S. Proskurina, E. Alakangas, J. Heinimö, M. Mikkilä, and E. Vakkilainen, "A survey analysis of the wood pellet industry in Finland: future perspectives," Energy, vol. 118, pp. 692-704, 2017.

[26] B. Coelho, A. Oliveira, P. Schwarzbözl, and A. Mendes, "Biomass and central receiver system (CRS) hybridization: integration of syngas/biogas on the atmospheric air volumetric CRS heat recovery steam generator duct burner," Renewable Energy, vol. 75, pp. 665-674, 2015.

[27] M. S. Roni, S. Chowdhury, S. Mamun, M. Marufuzzaman, W. Lein, and S. Johnson, "Biomass co-firing technology with policies, challenges, and opportunities: a global review," Renewable and Sustainable Energy Reviews, vol. 78, pp. 10891101, 2017.

[28] E. Toklu, "Biomass energy potential and utilization in Turkey," Renewable Energy, vol. 107, pp. 235-244, 2017.

[29] S. Proskurina, J. Heinimö, F. Schipfer, and E. Vakkilainen, "Biomass for industrial applications: the role of torrefaction," Renewable Energy, vol. 111, pp. 265-274, 2017.

[30] M. M. O. Carvalho, M. Cardoso, and E. K. Vakkilainen, "Biomass gasification for natural gas substitution in iron ore pelletizing plants," Renewable Energy, vol. 81, pp. 566-577, 2015.

[31] R. García, C. Pizarro, A. G. Lavín, and J. L. Bueno, "Biomass sources for thermal conversion. Techno-economical overview," Fuel, vol. 195, pp. 182-189, 2017.
[32] C. M. S. D. Silva, A. D. C. O. Carneiro, B. R. Vital et al., "Biomass torrefaction for energy purposes-definitions and an overview of challenges and opportunities in Brazil," Renewable and Sustainable Energy Reviews, vol. 82, pp. 2426-2432, 2018.

[33] Y. Xu, Y. Wang, Y. Chen et al., "Characterization of fine and carbonaceous particles emissions from pelletized biomasscoal blends combustion: implications on residential crop residue utilization in China," Atmospheric Environment, vol. 141, pp. 312-319, 2016.

[34] J. Ahn and J. H. Jang, "Combustion characteristics of a 16 step grate-firing wood pellet boiler," Renewable Energy, vol. 129, pp. 678-685, 2018.

[35] C. Ndibe, J. Maier, and G. Scheffknecht, "Combustion, cofiring and emissions characteristics of torrefied biomass in a drop tube reactor," Biomass and Bioenergy, vol. 79, pp. 105115, 2015.

[36] A. Kraszkiewicz, A. Przywara, M. Kachel-Jakubowska, and E. Lorencowicz, "Combustion of plant biomass pellets on the grate of a low power boiler," Agriculture and Agricultural Science Procedia, vol. 7, pp. 131-138, 2015.

[37] L. Chai and C. M. Saffron, "Comparing pelletization and torrefaction depots: optimization of depot capacity and biomass moisture to determine the minimum production cost," Applied Energy, vol. 163, pp. 387-395, 2016.

[38] H. Chu, L. Xiang, X. Nie, Y. Ya, M. Gu, and E. Jiaqiang, "Laminar burning velocity and pollutant emissions of the gasoline components and its surrogate fuels: a review," Fuel, vol. 269, p. 117451, 2020.

[39] G. Wu, D. Wu, Y. Li, and L. Meng, "Effect of acetone-nbutanol-ethanol (ABE) as an oxygenate on combustion, performance, and emission characteristics of a spark ignition engine," Journal of Chemistry, vol. 2020, Article ID 7468651, 11 pages, 2020.

[40] Q. Zuo, Y. Xie, Q. Guan et al., "Performance enhancement of a gasoline dual-carrier catalytic converter of the gasoline engine in the reaction equilibrium process," Energy Conversion and Management, vol. 204, Article ID 112325, 2020.

[41] Q. Zuo, Y. Xie, E. Jiaqiang et al., "Effect of different exhaust parameters on NO conversion efficiency enhancement of a dual-carrier catalytic converter in the gasoline engine," Energy, vol. 191, Article ID 116521, 2020.

[42] Q. Zuo, Y. Tang, W. Chen, J. Zhang, L. Shi, and Y. Xie, "Effects of exhaust parameters on gasoline soot regeneration performance of a catalytic gasoline particulate filter in equilibrium state," Fuel, vol. 265, Article ID 117001, 2020.

[43] E. Jiaqiang, M. Zhao, Q. Zuo et al., "Effects analysis on diesel soot continuous regeneration performance of a rotary microwave-assisted regeneration diesel particulate filter," Fuel, vol. 260, p. 116353, 2020.

[44] K. Wei, Y. Yang, H. Zuo, and D. Zhong, "A review on ice detection technology and ice elimination technology for wind turbine," Wind Energy, vol. 23, no. 3, pp. 433-457, 2020.

[45] B. Zhang, H. Zuo, Z. Huang, J. Tan, and Q. Zuo, "Endpoint forecast of different diesel-biodiesel soot filtration process in diesel particulate filters considering ash deposition," Fuel, vol. 271, Article ID 117678, 2020.

[46] G. Liao, E. Jiaqiang, F. Zhang, J. Chen, and E. Leng, "Leng. Advanced exergy analysis for optimized ORC-based layout to recover waste heat of flue gas in coal-fired plants," Applied Energy, vol. 266, Article ID 114891, 2020. 